\title{
Study on Sensory Quality, Antioxidant Properties, and Maillard Reaction Products Formation in Rye-Buckwheat Cakes Enhanced with Selected Spices
}

\author{
Małgorzata Przygodzka, ${ }^{1}$ Henryk Zieliński, ${ }^{1}$ Zuzana Ciesarová, ${ }^{2}$ \\ Kristina Kukurová, ${ }^{2}$ and Grzegorz Lamparski ${ }^{1}$ \\ ${ }^{1}$ Division of Food Science, Institute of Animal Reproduction and Food Research of the Polish Academy of Sciences, Tuwima 10, \\ P.O. Box 55, 10-748 Olsztyn 5, Poland \\ ${ }^{2}$ National Agriculture and Food Centre, Food Research Institute, Priemyselná 4, P.O. Box 25, 82475 Bratislava 26, Slovakia \\ Correspondence should be addressed to Małgorzata Przygodzka; m.przygodzka@pan.olsztyn.pl
}

Received 30 April 2015; Accepted 8 July 2015

Academic Editor: Francisco J. Morales

Copyright ( 2015 Małgorzata Przygodzka et al. This is an open access article distributed under the Creative Commons Attribution License, which permits unrestricted use, distribution, and reproduction in any medium, provided the original work is properly cited.

The effect of selected spices included in the recipe of rye-buckwheat cakes on sensory quality, nutritional value, and Maillard reaction (MR) products formation was addressed in this study. The cakes with cloves, nutmeg, allspice, cinnamon, vanilla, and spice mix addition revealed the highest overall quality values. Cakes enriched with cloves, allspice, and spice mix showed the highest rutin content and almost threefold higher available lysine contents whereas cakes enhanced with mix, cloves, and cinnamon were the richest source of phenolic compounds. The highest antioxidant capacity showed cakes with cloves and spice mix. The furosine, a marker of early stage of MR, was decreased in cakes with cloves, allspice, spice mix, and vanilla whereas fluorescent intermediatory compounds were reduced in cakes enhanced with cloves, allspice, and cinnamon. In contrast, browning index was increased as compared to cakes without spices. The FAST index was significantly lowered in all cakes enriched with spices, especially with cloves, allspice, and mix addition. The presence of cloves, allspice, and vanilla in cake formula was the most efficient in acrylamide strategy. It can be suggested that cloves, allspice, and vanilla might be used for production of safety and good quality cakes.

\section{Introduction}

The complex cascade of interactions occurring at elevated temperature between carbonyl groups of sugars and amino groups of amino acids/proteins is called Maillard reaction (MR) [1]. According to new insights, hundreds of different compounds within different chemical groups with varied biological and physiochemical properties created via MR are responsible for the development of color, taste, and aroma as well as the nutrients loss of thermally treated food [2]. Virág et al. [3] stated that remaining lysine after baking process is a good indicator of the progress of MR and is important to monitor its content as essential amino acids. Several unfavorable food contaminants are simultaneously formed in thermal processing. During early step of $\mathrm{MR}$, the nutritionally valued available lysine can be converted into furosine, a heat-treatment marker $[4,5]$. Another undesirable MR component, acrylamide, with probable mutagenic/carcinogenic or neurotoxic properties may be formed in increased amount [6]. The advanced stage of MR is characterized by the formation of fluorescence compounds with regard to advanced glycation end-products formation and monitoring protein degradation by FAST index $[7,8]$. Positively, melanoidins formed in the final stage of MR are responsible for the colour formation and possess the ability to scavenge free radicals [9].

It was concerned that MR products formation in model systems and food products can be reduced/increased by an application of substances having a high antioxidant potential [10-12]. The compilation of current trends in bakery technology to enhancement antioxidant activity of wheat products was widely described by Dziki et al. [13]. At the top of the list, 
spices and herbs have been suggested as a well-recognised source of compounds with antioxidant potential [14-16]. Recently, the inquisitive studies on antioxidant capacities of spices employing updated analytical methods were reported by Przygodzka et al. [17]. According to data collected in Food Frequency Questionnaire, the average of spices/herbs intake was estimated as 1.1 grams per day for one person which revealed that spices are important contributor of antioxidants to our diet [18]. Spices are mainly employed as flavoring and color agents whereas potential use for preservation food and disease prevention has been already studied [19-21]. Spice application was demonstrated by Illupapalayam et al. [22]. Their probiotic-yogurt with cardamom, cinnamon, and nutmeg has increased sensorial acceptability among consumers, besides spice addition increased overall antioxidant activity of this functional product.

Recently, consumers seeking new food products are focused on joining two aspects: a taste and functional properties [23]. The functional properties of innovative products in prevention or therapy support in selected diseases are desirable. Anticancer, antiallergic, antiviral, cholesterolreducing, blood pressure-reducing, and arteriosclerosisreducing effects were ascribed as buckwheat's healing effects [24]. In this trend buckwheat-based product with spices addition can be good alternative to inclusion in varied and balanced diet. Moreover, several studies approved consumer acceptability of buckwheat-based products [25-28]. The high sensorial acceptability of $30 \%$ buckwheat flour incorporation in baked products was reached.

In this study the recipe of rye-buckwheat cakes was enriched with one spice from the list including anise, allspice, cardamom, cinnamon, cloves, coriander, fennel, ginger, nutmeg, star anise, vanilla, white pepper, and commercial spice mix for ginger cakes. The sensory evaluation of cakes was used as a tool for selection cakes accepted by sensory panel consumers.

In this study, analysis of quercetin 3-rhamnosylglucoside (rutin), the main buckwheat flavonoid, available lysine, and total phenolics contents (TPC) and the antioxidant capacity of cakes using extracts scavenging activity against $\mathrm{ABTS}^{\bullet+}$ radical cation and 1,1-diphenyl-2-picrylhydrazyl radical $\left(\mathrm{DPPH}^{\bullet}\right)$ and against superoxide anion radicals $\left(\mathrm{O}_{2}{ }^{--}\right)$ measured by the photochemiluminescence method (PCL) were conducted. To monitor MR progress furosine, acrylamide, fluorescent compounds, and melanoidins as makers were chosen whereas acrylamide concentration was investigated as representative of toxic contaminants. To determine the impact of thermal treatment on protein damage, FAST index was calculated.

The aim of this study was to find out an impact of selected spices included in the recipe of rye-buckwheat cakes on their sensory quality, nutritional value, and formation of Maillard reaction products.

\section{Materials and Methods}

2.1. Chemicals and Reagents. 2,2'-Azinobis(3-ethylbenzothiazoline-6-sulphonic acid) diammonium salt (ABTS), 6hydroxy-2,5,7,8-tetramethylchroman-2-carboxylic acid (Trolox),
TABLE 1: Formula of rye-buckwheat cakes enhanced with selected spices: anise, allspice, cardamom, cinnamon, cloves, coriander, fennel, ginger, nutmeg, star anise, vanilla, white pepper, and commercial mix of spices for ginger cake.

\begin{tabular}{lcc}
\hline Ingredients & Control cake & $\begin{array}{c}\text { Rye-buckwheat } \\
\text { cake with spice } \\
\text { addition }\end{array}$ \\
\hline Rye flour (T-720) [g] & 70 & 70 \\
Flour from buckwheat & 30 & 30 \\
groats [g] & 50 & 50 \\
Buckwheat honey [g] & 20 & 20 \\
Sugar [g] & 3 & 3 \\
Baking powder [g] & 25 & 25 \\
Butter [g] & 0 & 2 \\
Selected spice [g] & &
\end{tabular}

rutin (quercetin-3-rutinoside), 2,2-diphenyl-1-picrylhydrazyl (DPPH), lysine ( $\mathrm{N}^{\alpha}$-acetyl-L-lysine), and pronase E (Streptomyces griseus lyoph.) were purchased from Sigma (Sigma Chemical Co., St. Louis, MO, USA). PCL ACW (Antioxidant Capacity of Water-soluble substances) kit for PCL assay was from Analytik Jena AG (Jena, Germany). o-Phthaldialdehyde for fluorescence (OPA) and sodium dodecyl sulfonate (SDS) were supplied by Fluka (Buchs, Switzerland). Furosine (2furoylmethyl-lysine) was purchased from PolyPeptide (Strasbourg, France). Acrylamide-d3 (98\%) was purchased from Cambridge Isotope Laboratories (USA). Acetonitrile and methanol (HPLC purity) were provided by POCh (Gliwice, Poland). Trifluoroacetic acid, $\beta$-mercaptoethanol, zinc sulphate, and potassium ferrocyanide were provided by Merck (Darmstadt, Germany). Water was purified with Milli-Qsystem (Millipore, Bedford, USA).

\subsection{Formulation of Rye-Buckwheat Ginger Cakes Enhanced} with Spices. The cakes were baked using rye flour blended with flour from roasted buckwheat groats in ratio 70:30 $(\mathrm{w} / \mathrm{w})$. The making process involved dough preparation by mixing flours, honey, and sugar. Each one of the selected spices ( $1 \%$ of formula; w/w) from the list, anise, allspice, cardamom, cinnamon, cloves, coriander, fennel, ginger, nutmeg, star anise, vanilla, white pepper, and commercial spice mix for ginger cake, was used in rye-buckwheat cakes recipe. According to the producer's declaration, commercial spice mix contained cinnamon, pepper, clove, anise, coriander, fennel, and nutmeg. The amounts of ingredients added to make each type of cake are presented in Table 1 . The dough was cut into $0.5 \mathrm{~cm}$ thick discs of $5.5 \mathrm{~cm}$ diameter and baked at $180^{\circ} \mathrm{C}$ for $18 \mathrm{~min}$ in a DC-32E electric oven (Sveba-Dahlen, Fristad, Sweden). Finally, the cakes were freeze-dried and ground into powder. The powdered samples were sieved through a 60 -mesh screen and then stored at $-20^{\circ} \mathrm{C}$ until being analyzed.

2.3. Sensory Evaluation. 24 attributes related to the appearance, odour, taste, and texture of rye-buckwheat ginger cakes with spices were selected and thoroughly used during profiling procedure. Sensory characteristics and overall quality 
of ginger cakes were evaluated according to international unified standards [29]. A 6-member trained panel judged ginger cakes in a 10 -point scale ( 0 for weak, 10 for very good) using quantitative descriptive analysis (QDA) to determine differences between each type of ginger cakes [30]. The description of sample preparation and standardized procedure of sensory evaluation were in detail presented by Zieliński et al. [31].

Overall acceptability of each sample was evaluated in relation to the sensory preferences on the basis of overall appearance, aroma, taste, and texture, in a ten-point hedonic scale, where $0=$ not accepted and $10=$ fully accepted. The profiling analysis of all samples was run in duplicate (two series) proceeded by introduction session. Ginger cakes were considered acceptable if their mean scores for overall acceptability were above 6 .

2.4. Preparation of Extracts from Rye-Buckwheat Cakes. Ryebuckwheat cake powders (100 mg) were extracted with $1 \mathrm{~mL}$ of $65 \%(\mathrm{v} / \mathrm{v})$ ethanol. After ultrasonic vibration for $30 \mathrm{~s}$, the solution was mixed and centrifuged for $5 \mathrm{~min}$ at $5000 \times \mathrm{g}$ at $4^{\circ} \mathrm{C}$. That step was repeated 5 times and the supernatants were collected into $5 \mathrm{~mL}$ flask. Final extracts concentration was $20 \mathrm{mg} / \mathrm{mL}$. Ethanol extracts were prepared in triplicate. Next extracts were stored at $-20^{\circ} \mathrm{C}$ until analysis of rutin content, total phenolic compounds (TPC), and antioxidant capacity (AC) by ABTS, DPPH, and PCL assays.

\subsection{Determination of Total Phenolic Content (TPC) and Rutin.} The TPC was determined with Folin-Ciocalteu reagent as it was described in detail by Przygodzka et al. [17]. TPC was standardized against gallic acid and expressed in terms of mg gallic acid equivalents (GAE)/g dry matter. The content of rutin in ginger cakes was determined with HPLC (Shimadzu, Japan) with UV detector (SPD-10A) set up at $330 \mathrm{~nm}$ as it was recently described by Zielińska et al. [32]. For quantitative analysis, rutin standard was prepared in triplicate at five concentrations within the range of $1.0-40 \mu \mathrm{M}$. All solutions were filtered through a $0.45 \mu \mathrm{m}$ nylon membrane before use. The results were expressed in $\mu \mathrm{g}$ per $\mathrm{g}$ of dry matter.

2.6. Antioxidant Capacity Determination. The antioxidant capacity of rye-buckwheat cakes enhanced with spices was determined by ABTS, DPPH, and photochemiluminescence (PCL) assays as it was described in detail by Przygodzka et al. [17]. The results of ABTS, DPPH, and PCL method were expressed as $\mu \mathrm{mol}$ Trolox/g of dry matter.

2.7. Available Lysine Content Determination. The OPA assay as described by Michalska et al. [33] was employed to determine available lysine content using the microplate reader (Infinite M1000 PRO, Tecan, Switzerland). Exactly $50 \mu \mathrm{L}$ of sample, $100 \mu \mathrm{L}$ of OPA reagent, and $100 \mu \mathrm{L}$ of water were added to well and incubated for 3 min (96-well microplate, Porvair Sciences). Then the fluorescence reading was measured at excitation wavelength $340 \mathrm{~nm}$ and emission wavelength $455 \mathrm{~nm}$. Quantitative analysis was performed by the external standard method, employing a calibration curve of $\mathrm{N}^{\alpha}$-acetyl-L-lysine ranging from 10 to $250 \mu \mathrm{M}$. Each result is a mean of three independent extractions.

\subsection{Maillard Reaction Products Determination}

2.8.1. Furosine Content Determination. According to DelgadoAndrade et al. [7], $30 \mathrm{mg}$ of cake sample was hydrolysed with $4 \mathrm{~mL}$ of $4.9 \mathrm{M} \mathrm{HCl}$ at $110^{\circ} \mathrm{C}$ for $23 \mathrm{~h}$ in a Pyrex screw-capped vial with PTFE-faced septa. Hydrolysis tubes must be sealed under nitrogen. After that the hydrolysate was centrifuged for $10 \mathrm{~min}$. A $0.5 \mathrm{~mL}$ portion of the supernatant was applied to a Sep-pak C18 cartridge (Millipore) conditioned with $5 \mathrm{~mL}$ of methanol and $10 \mathrm{~mL}$ of distilled water and then eluted with $3 \mathrm{~mL}$ of $3 \mathrm{M} \mathrm{HCL}$ and evaporated under vacuum. The dried sample was dissolved in $1 \mathrm{~mL}$ of a mixture of water, acetonitrile, and formic acid $(95: 5: 0.2)$ before HPLC analysis.

The furosine was quantified by HPLC system (Shimadzu, Japan) comprised of a controller (SCL-10AVP) and a PDA detector (SPD-M10AVP). A Cadenza CD-C18 column $(250 \times$ $2 \mathrm{~mm}, 3 \mu \mathrm{m}$, Imtakt, Japan) at $35^{\circ} \mathrm{C}$. The mobile phase consisted of a solution of $5 \mathrm{mM}$ sodium heptane sulfonate containing $20 \%$ of acetonitrile and $0.2 \%$ of formic acid. The elution was isocratic and the flow rate was $0.2 \mathrm{~mL} / \mathrm{min}$. The UV detector was set at $280 \mathrm{~nm}$. Calibration curve was made by the external standard of furosine $0.2-9 \mu \mathrm{g} / \mathrm{mL}$.

2.8.2. Measurement of MRP Fluorescence Intermediatory Compounds and Calculation FAST Index. The fluorescence of free and total intermediary compounds (FIC) was determined after sample extraction and further enzymatic hydrolysis using pronase E according to Delgado-Andrade et al. [34]. Readings were recorded in a luminescent spectrofluorimeter (LS 50B, Perkin Elmer, USA) setting at $\lambda_{\text {ext. }}=347 \mathrm{~nm}$ and $\lambda_{\mathrm{em}}$. $=415 \mathrm{~nm}$. Tryptophan fluorescence $\operatorname{Trp}_{\mathrm{FL}}$ was measured at $\lambda_{\text {ext. }}=290 \mathrm{~nm}$ and $\lambda_{\text {em. }}=340 \mathrm{~nm}$. Results are expressed in fluorescence intensity (FI) per $\mathrm{mg}$ of sample DM. The FAST index was calculated as recently reported by Zieliński et al. [31] with a one-novelty modification based on the use of fluorescent compounds linked to proteins for index calculation. The samples were analyzed in triplicate and FAST index data were expressed as a percentage (\%).

2.8.3. Brown Pigments Assay. Formation of brown pigments was estimated as reported in detail by Zieliński et al. [31]. All measurements were performed in triplicate. Results were expressed as arbitrary absorbance units.

2.8.4. Acrylamide Content. Extraction of acrylamide from the samples and LC/ESI-MS-MS analyses were performed as described in detail by Marková et al. [10].

2.8.5. Statistical Analysis. The results of the chemical analyses are given as the means and the standard deviation of three independent measurements. Statistical one-way analysis of variance (ANOVA) using Fischer test was performed. The significance level was set at $P<0.05$. The correlation test between rutin content, antioxidant ability, and MRPs formation was performed and the Pearson correlation coefficients were calculated. Statistical analyses were performed using software package (StatSoft Inc., v. 7.1, Tulsa, OK, USA). 
TABLE 2: Descriptive analysis of results based on the analysis of variance (ANOVA) performed on rye-buckwheat cakes with spice addition.

\begin{tabular}{|c|c|c|c|c|c|c|c|c|}
\hline \multirow{2}{*}{\multicolumn{2}{|c|}{ Attribute }} & \multicolumn{7}{|c|}{ Rye-buckwheat cakes } \\
\hline & & Control & Cloves & Nutmeg & Allspice & Cinnamon & Vanilla & Spice mix \\
\hline 1 & Brown colour & $8.56^{\mathrm{a}}$ & $7.42^{\mathrm{b}}$ & $5.28^{\mathrm{d}}$ & $6.91^{\mathrm{bc}}$ & $5.99^{\mathrm{cd}}$ & $6.93^{\mathrm{bc}}$ & $7.18^{\mathrm{b}}$ \\
\hline 2 & Sweet o. & $3.92^{\mathrm{a}}$ & $4.17^{\mathrm{a}}$ & $4.2^{\mathrm{a}}$ & $4.73^{\mathrm{a}}$ & $5.13^{\mathrm{a}}$ & $4.92^{\mathrm{a}}$ & $4.10^{\mathrm{a}}$ \\
\hline 3 & Dried mushroom o. & $0.53^{\mathrm{a}}$ & $0.13^{\mathrm{b}}$ & $0.16^{\mathrm{b}}$ & $0.05^{\mathrm{b}}$ & $0.07^{\mathrm{b}}$ & $0.05^{\mathrm{b}}$ & $0.17^{\mathrm{b}}$ \\
\hline 4 & Biscuit o. & $1.70^{\mathrm{c}}$ & $2.68^{\mathrm{bc}}$ & $3.26^{\mathrm{ab}}$ & $4.03^{\mathrm{a}}$ & $3.83^{\mathrm{ab}}$ & $4.10^{\mathrm{a}}$ & $3.20^{\mathrm{ab}}$ \\
\hline 5 & Anise o. & $0.90^{\mathrm{a}}$ & $0.02^{\mathrm{a}}$ & $0.02^{\mathrm{a}}$ & $0.01^{\mathrm{a}}$ & $0.16^{\mathrm{a}}$ & $0.02^{\mathrm{a}}$ & $0.09^{\mathrm{a}}$ \\
\hline 6 & Cinnamic o. & $0.03^{\mathrm{b}}$ & $0.03^{\mathrm{b}}$ & $0.03^{\mathrm{b}}$ & $0.02^{\mathrm{b}}$ & $2.85^{\mathrm{a}}$ & $0.52^{\mathrm{b}}$ & $0.33^{\mathrm{b}}$ \\
\hline 7 & Cloves o. & $0.01^{\mathrm{b}}$ & $2.92^{\mathrm{a}}$ & $0.10^{\mathrm{b}}$ & $0.61^{\mathrm{b}}$ & $0.22^{\mathrm{b}}$ & $0.03^{\mathrm{b}}$ & $0.46^{\mathrm{b}}$ \\
\hline 8 & White pepper o. & $0.86^{\mathrm{a}}$ & $0.02^{\mathrm{a}}$ & $0.10^{\mathrm{a}}$ & $0.02^{\mathrm{a}}$ & $0.02^{\mathrm{a}}$ & $0.01^{\mathrm{a}}$ & $0.06^{\mathrm{a}}$ \\
\hline 9 & Vanilla o. & $0.03^{\mathrm{b}}$ & $0.02^{\mathrm{b}}$ & $0.02^{\mathrm{b}}$ & $0.03^{\mathrm{b}}$ & $0.07^{\mathrm{b}}$ & $2.33^{\mathrm{a}}$ & $0.08^{\mathrm{b}}$ \\
\hline 10 & Spicy o. & $3.53^{\mathrm{ab}}$ & $4.13^{\mathrm{a}}$ & $2.39^{b c}$ & $3.16^{\mathrm{ab}}$ & $1.74^{\mathrm{c}}$ & $1.91^{\mathrm{c}}$ & $2.59^{b c}$ \\
\hline 11 & Sweet $\mathrm{t}$. & $3.73^{c}$ & $4.22^{\mathrm{bc}}$ & $4.80^{\mathrm{abc}}$ & $5.51^{\mathrm{ab}}$ & $5.59^{\mathrm{ab}}$ & $6.14^{\mathrm{a}}$ & $4.71^{b c}$ \\
\hline 12 & Bitter t. & $4.21^{\mathrm{a}}$ & $2.54^{\mathrm{b}}$ & $1.10^{\mathrm{bc}}$ & $1.44^{\mathrm{bc}}$ & $0.44^{\mathrm{c}}$ & $1.19^{b c}$ & $1.47^{\mathrm{bc}}$ \\
\hline 13 & Anise $\mathrm{t}$. & $1.74^{\mathrm{a}}$ & $0.46^{\mathrm{b}}$ & $0.08^{\mathrm{b}}$ & $0.04^{\mathrm{b}}$ & $0.27^{\mathrm{b}}$ & $0.03^{\mathrm{b}}$ & $0.33^{\mathrm{b}}$ \\
\hline 14 & Cinnamic t. & $0.02^{\mathrm{b}}$ & $0.03^{\mathrm{b}}$ & $0.02^{\mathrm{b}}$ & $0.03^{\mathrm{b}}$ & $2.58^{\mathrm{a}}$ & $0.05^{\mathrm{b}}$ & $0.05^{\mathrm{b}}$ \\
\hline 15 & Cloves t. & $0.03^{\mathrm{b}}$ & $3.62^{\mathrm{a}}$ & $0.03^{\mathrm{b}}$ & $0.02^{\mathrm{b}}$ & $0.06^{\mathrm{b}}$ & $0.03^{\mathrm{b}}$ & $0.22^{\mathrm{b}}$ \\
\hline 16 & White pepper $\mathrm{t}$. & $0.04^{\mathrm{a}}$ & $0.02^{\mathrm{a}}$ & $0.02^{\mathrm{a}}$ & $0.86^{\mathrm{a}}$ & $0.03^{\mathrm{a}}$ & $0.02^{\mathrm{a}}$ & $0.01^{\mathrm{a}}$ \\
\hline 17 & Vanilla t. & $0.02^{\mathrm{b}}$ & $0.03^{\mathrm{b}}$ & $0.11^{\mathrm{b}}$ & $0.02^{\mathrm{b}}$ & $0.34^{\mathrm{b}}$ & $2.88^{\mathrm{a}}$ & $0.14^{\mathrm{b}}$ \\
\hline 18 & Ginger t. & $0.03^{\mathrm{a}}$ & $0.29^{\mathrm{a}}$ & $0.03^{\mathrm{a}}$ & $0.01^{\mathrm{a}}$ & $0.02^{\mathrm{a}}$ & $0.03^{\mathrm{a}}$ & $0.02^{\mathrm{a}}$ \\
\hline 19 & Spicy t. & $3.56^{\mathrm{a}}$ & $3.98^{\mathrm{a}}$ & $3.52^{\mathrm{a}}$ & $3.24^{\mathrm{a}}$ & $2.91^{\mathrm{a}}$ & $2.46^{\mathrm{a}}$ & $3.69^{\mathrm{a}}$ \\
\hline 20 & Pungent $\mathrm{t}$. & $1.64^{\mathrm{a}}$ & $0.52^{b c}$ & $0.81^{\mathrm{b}}$ & $0.14^{\text {cd }}$ & $0.15^{\mathrm{cd}}$ & $0.15^{\mathrm{cd}}$ & $0.09^{\mathrm{d}}$ \\
\hline 21 & Aftertaste & $3.82^{\mathrm{a}}$ & $4.36^{\mathrm{a}}$ & $2.01^{\mathrm{b}}$ & $1.55^{\mathrm{b}}$ & $1.77^{\mathrm{b}}$ & $1.68^{\mathrm{b}}$ & $1.57^{\mathrm{b}}$ \\
\hline 22 & Hardness & $7.67^{\mathrm{ab}}$ & $7.07^{\mathrm{b}}$ & $7.67^{\mathrm{ab}}$ & $7.88^{\mathrm{a}}$ & $8.03^{\mathrm{a}}$ & $7.99^{\mathrm{a}}$ & $7.10^{\mathrm{b}}$ \\
\hline 23 & Crispness & $7.90^{\mathrm{abc}}$ & $8.10^{\mathrm{a}}$ & $7.99^{\mathrm{ab}}$ & $7.63^{c}$ & $6.45^{\mathrm{e}}$ & $7.69^{b c}$ & $7.07^{\mathrm{d}}$ \\
\hline
\end{tabular}

Means in each rows with the same letters do not have significant differences (Fisher test, $P<0.05$ ). o.: attributes of odour; t.: attributes of taste.

\section{Results and Discussion}

3.1. Sensorial Evaluation. In the literature elaborated buckwheat-based products such as biscuit from rye and buckwheat flour with ginger nut [28], crackers from cornmeal and buckwheat flour [25], gluten-free bread formulation containing $30 \%$ of buckwheat flour [27], and wheat-buckwheat bread [26] were found to be acceptable with respect to all sensory attributes and confirmed $30 \%$ substitution of buckwheat as the optimum supplementation level that offered the best compromise for the highest acceptability.

In this study, the sensory analysis was taken as a tool for selection of the rye-buckwheat ginger cakes enhanced with selected spices for further investigation of Maillard reaction products. Based on the hedonic scale (Figure 1), the highest sensory score was noted for rye-buckwheat cakes with vanilla and cinnamon.

The cakes with allspice were also scored very high. Except for rye-buckwheat cakes with white pepper, all samples were scored higher than control one. Taking into account the overall acceptability rating, it was concluded that rye-buckwheat cakes with addition of clove, cinnamon, allspice, nutmeg, vanilla, and spice mix could be baked with satisfactory overall quality. In order to find attributes having impact on the sensory quality of rye-buckwheat cakes with spices, a quantitative descriptive analysis (QDA) was performed. The sensory profiles of control rye-buckwheat cakes and ginger cakes

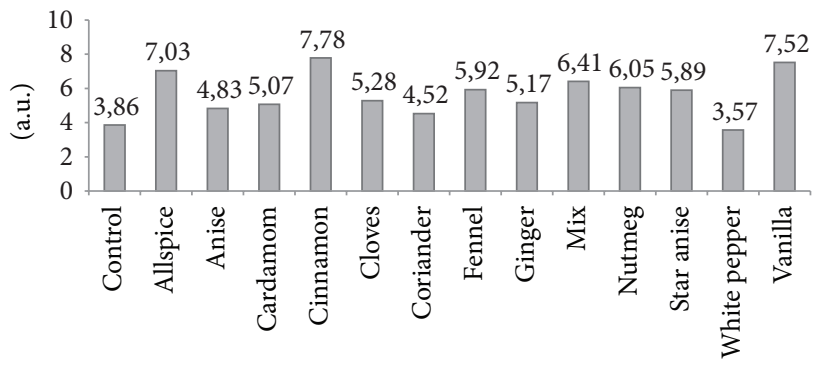

FIGURE 1: The overall quality of rye-buckwheat cakes enhanced with selected spices. Results are reported as arbitrary units.

enriched with clove, cinnamon, allspice, nutmeg, vanilla, and spice mix are shown as spider diagrams in Figure 2 whereas the mean sensory ratings for the samples and the analysis of variance are presented in Table 2.

ANOVA showed that there were significant differences in the intensity of attributes such as the following: brown colour; odour descriptors: "dried mushroom," "biscuit," "cinnamic," "cloves," "vanilla," and "spicy"; taste descriptors: sweet, bitter, "anise," "cinnamic," “cloves," "vanilla," pungent, aftertaste, and mouth feel: hardness and crunchiness. According to available sources, salicylaldehyde and 2,5-dimethyl-4-hydro$\mathrm{xy}-3(2 \mathrm{H})$-furanone (strawberry-like), (E,E)-2,4-decadienal (deep fat flavor), phenylacetaldehyde (honey-like, sweet, rose, 
TABLE 3: The content of rutin, total phenolic compounds, and antioxidant capacity of rye-buckwheat cakes enhanced with selected spices.

\begin{tabular}{|c|c|c|c|c|c|}
\hline \multirow{2}{*}{ Type of cake } & \multirow{2}{*}{ Rutin } & \multirow{2}{*}{ TPC } & \multicolumn{3}{|c|}{ Antioxidant capacity } \\
\hline & & & $\mathrm{DPPH}$ & PCL & ABTS \\
\hline Control & $35.64 \pm 0.64^{\mathrm{g}}$ & $2.30 \pm 0.22^{\mathrm{f}}$ & $6.35 \pm 0.27^{\mathrm{d}}$ & $4.87 \pm 0.21^{\mathrm{d}}$ & $16.14 \pm 0.08^{\mathrm{e}}$ \\
\hline Vanilla & $37.77 \pm 1.51^{\mathrm{d}}$ & $3.04 \pm 0.30^{\mathrm{e}}$ & $10.46 \pm 0.28^{\mathrm{c}}$ & $4.68 \pm 0.18^{\mathrm{e}}$ & $36.55 \pm 1.33^{\mathrm{b}}$ \\
\hline Cinnamon & $39.60 \pm 0.30^{\mathrm{g}}$ & $3.64 \pm 0.18^{\mathrm{d}}$ & $10.17 \pm 0.49^{c}$ & $5.60 \pm 0.33^{c}$ & $29.79 \pm 1.14^{\mathrm{c}, \mathrm{d}}$ \\
\hline Cloves & $256.14 \pm 28.61^{\mathrm{a}}$ & $7.94 \pm 0.04^{\mathrm{b}}$ & $18.34 \pm 1.07^{\mathrm{a}}$ & $19.51 \pm 0.35^{\mathrm{a}}$ & $30.85 \pm 0.28^{c}$ \\
\hline Allspice & $89.18 \pm 13.83^{\mathrm{b}}$ & $5.76 \pm 0.50^{c}$ & $8.35 \pm 0.59^{\mathrm{d}}$ & $5.98 \pm 0.32^{\mathrm{c}}$ & $30.73 \pm 0.48^{c}$ \\
\hline Nutmeg & $35.68 \pm 3.89^{\mathrm{e}}$ & $3.69 \pm 0.15^{\mathrm{d}}$ & $8.14 \pm 0.07^{\mathrm{d}}$ & $4.40 \pm 0.06^{\mathrm{f}}$ & $28.37 \pm 0.18^{\mathrm{d}}$ \\
\hline Spice mix & $50.24 \pm 0.09^{c}$ & $11.13 \pm 0.07^{\mathrm{a}}$ & $12.39 \pm 0.46^{\mathrm{b}}$ & $6.24 \pm 0.27^{\mathrm{b}}$ & $61.34 \pm 0.65^{\mathrm{a}}$ \\
\hline
\end{tabular}

Rutin content is expressed in $\mu \mathrm{g} / \mathrm{g}$ DM.

TPC is expressed in mg of gallic acid equivalents/g of dry matter (DM).

Antioxidant capacity is expressed in $\mu \mathrm{mol}$ of Trolox equivalents/g DM.

Values are means \pm standard deviation $(n=3)$. Values in each column with different small superscript letters are significantly different $(P<0.05)$.

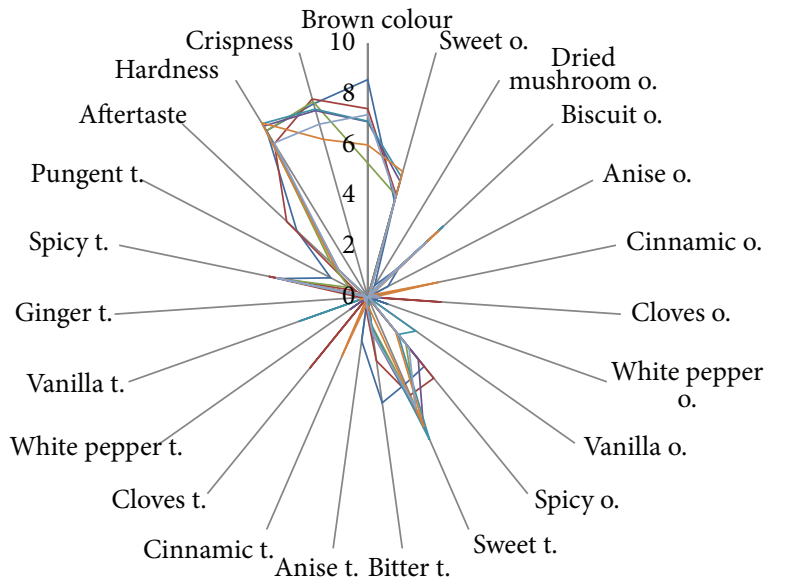

$$
\begin{aligned}
& \text { Control cake } \\
& \text { _ Cake with cloves } \\
& \text { C Cake with nutmeg } \\
& \text { Cake with allspice }
\end{aligned}
$$$$
\begin{aligned}
& \text { Cake with vanilla } \\
& \text { Cake with cinnamon } \\
& \text { Cake with spice mix }
\end{aligned}
$$

FIGURE 2: Sensory profiles of rye-buckwheat cake without spice (control cake) and rye-buckwheat cakes with selected spices: cloves, nutmeg, allspice, vanilla, cinnamon, and spice mix. o.: attributes of odour; t.: attributes of taste.

green, and grassy), 2-methoxy-4-vinylphenol (spicy, peanut, and wine-like), (E)-2-nonenal (cardboard), decanal, and hexanal (freshly cut grass) were recognized as compounds with the highest contribution to the aroma of buckwheat [35]. The positive effect of spices supplementation was observed in significant increasing of bitter and pungent taste $(P<$ 0.05), 9.5 times lower for cakes with cinnamon and 12 times for cakes with allspice. Moreover, the generally regarded as unpleasant bitter taste can be provided in rye-buckwheat cakes by formation of alkylpyridines in Maillard reaction [36]. Spices addition masked the negative attributes of ryebuckwheat cakes whereas positive ones increased biscuit odour up to $42 \%$ after vanilla addition. The low contribution of intensity of brown colour on overall quality according to negative correlation $(r=-0.63)$ was noted. Therefore, the sensory evaluation proved that addition of selected spices to rye-buckwheat cakes formulation increased the sensory quality of products.

\subsection{Total Phenolic Compounds (TPC) and Rutin Contents in} Rye-Buckwheat Cakes with Spices. The content of TPC and rutin in rye-buckwheat cakes enhanced with selected spices is compiled in Table 3 . The addition of spices to rye-buckwheat cakes formula resulted in increase of TPC in comparison to control cake. The highest TPC was found in rye-buckwheat cakes enhanced with spice mix, cloves, and cinnamon, being 4.84-fold, 4.32-fold, and 2.50-fold higher as compared to TPC noted in rye-buckwheat cakes without spices addition. The high TPC content noted for these cakes was in relation to the high TPC content found previously for spice mix, cloves, and cinnamon as it was described by Przygodzka et al. [17].

The buckwheat flour is known as good source of flavonoids, mainly rutin [37]. In our study, a significantly higher rutin content was found in rye-buckwheat cakes enriched with cloves and allspice as compared to the enrichment with vanilla, cinnamon, nutmeg, and spice $\operatorname{mix}(P<0.05)$. Moreover, about 7.2-fold and 2.5-fold higher rutin was noted in cakes enhanced with clove and allspice as compared to ryebuckwheat cakes without any spices. The availability of rutin from cloves has been confirmed in previous investigation by Sofic et al. [38]. A weak correlation between rutin and TPC $(r=0.36)$ was observed in our study. Therefore, it can be suggested that not only rutin but also other flavonoids extracted from spices may contribute to the antioxidant capacity of rye-buckwheat cakes.

3.3. Antioxidant Capacity. The application of spices at the level of $1 \%$ in the formulation of rye-buckwheat cakes resulted in significant differences $(P<0.05)$ in the antioxidant capacity (AC) determined against $\mathrm{ABTS}^{\bullet+}, \mathrm{DPPH}^{\bullet}$, and $\mathrm{O}_{2}{ }^{-\bullet}$ radicals as presented in Table 3 . Ordered by antioxidant capacity provided by ABTS method, the rye-buckwheat cakes supplemented with spice mix showed the highest value, followed by those cakes enhanced with vanilla, cloves, allspice, cinnamon, and nutmeg. Significantly higher AC values were obtained for cakes with spice mix, cloves, and allspice, being 
TABLE 4: Data on Maillard reaction products in rye-buckwheat cakes with spices supplementation.

\begin{tabular}{|c|c|c|c|c|c|c|c|c|}
\hline Type of cake & $\begin{array}{c}\text { Available } \\
\text { lysine }(\mathrm{mg} / \mathrm{g})\end{array}$ & $\begin{array}{l}\text { Furosine } \\
(\mu \mathrm{g} / \mathrm{g})\end{array}$ & $\begin{array}{c}\text { Free FIC } \\
(\mathrm{FI} / \mathrm{mg} \mathrm{DM})\end{array}$ & $\begin{array}{c}\text { Total FIC } \\
\text { (FI/mg DM) }\end{array}$ & $\begin{array}{l}\text { FIC linked to } \\
\text { protein } \\
(\mathrm{FI} / \mathrm{mg} \mathrm{DM})\end{array}$ & $\begin{array}{c}\text { FAST index } \\
(\%)\end{array}$ & $\begin{array}{l}\text { Browning } \\
\text { index (AU) }\end{array}$ & $\begin{array}{c}\mathrm{ACR} \\
(\mu \mathrm{g} / \mathrm{kg} \mathrm{DM})\end{array}$ \\
\hline Control & $0.52 \pm 0.14^{\mathrm{e}}$ & $413.5 \pm 32.3^{\mathrm{a}}$ & $106.38 \pm 2.96^{\mathrm{a}}$ & $146.63 \pm 3.40^{\mathrm{a}}$ & $40.25 \pm 0.44^{\mathrm{b}}$ & $271.8 \pm 3.33^{\mathrm{a}}$ & $0.35 \pm 0.01^{f}$ & $248.0 \pm 3.5^{\mathrm{c}}$ \\
\hline Vanilla & $1.42 \pm 0.02^{\mathrm{c}}$ & $278.4 \pm 12.5^{c}$ & $106.89 \pm 2.81^{\mathrm{a}}$ & $142.89 \pm 9.28^{\mathrm{a}}$ & $36.00 \pm 2.09^{c}$ & $154.8 \pm 4.71^{\mathrm{b}}$ & $0.38 \pm 0.03^{e}$ & $225.1 \pm 2.3^{\mathrm{d}}$ \\
\hline Cinnamon & $1.41 \pm 0.01^{\mathrm{c}}$ & $323.3 \pm 18.7^{b}$ & $82.54 \pm 3.46^{c}$ & $117.30 \pm 4.62^{\mathrm{c}}$ & $34.76 \pm 1.16^{\mathrm{c}}$ & $133.7 \pm 0.81^{\mathrm{c}}$ & $0.51 \pm 0.01^{b c}$ & $296.1 \pm 7.3^{b}$ \\
\hline Cloves & $1.52 \pm 0.03^{\mathrm{b}}$ & $279.0 \pm 19.2^{c}$ & $72.97 \pm 4.68^{\mathrm{d}}$ & $91.88 \pm 4.89^{\mathrm{d}}$ & $18.91 \pm 0.21^{\mathrm{e}}$ & $68.5 \pm 2.89^{\mathrm{e}}$ & $0.53 \pm 0.01^{\mathrm{ab}}$ & $228.1 \pm 11.2^{\mathrm{d}}$ \\
\hline Allspice & $1.67 \pm 0.04^{\mathrm{a}}$ & $279.3 \pm 5.6^{c}$ & $82.18 \pm 3.75^{\mathrm{c}}$ & $113.12 \pm 6.67^{c}$ & $30.93 \pm 0.42^{\mathrm{d}}$ & $105.4 \pm 7.29^{d}$ & $0.46 \pm 0.02^{\mathrm{d}}$ & $220.8 \pm 8.2^{\mathrm{d}}$ \\
\hline Nutmeg & $0.99 \pm 0.03^{f}$ & $329.4 \pm 22.7^{\mathrm{b}}$ & $95.47 \pm 2.83^{\mathrm{b}}$ & $142.69 \pm 0.65^{\mathrm{a}}$ & $47.22 \pm 2.18^{\mathrm{a}}$ & $120.0 \pm 6.09^{\mathrm{d}}$ & $0.36 \pm 0.02^{\mathrm{ef}}$ & $260.6 \pm 18.0^{c}$ \\
\hline Spice mix & $1.32 \pm 0.04^{\mathrm{d}}$ & $73.6 \pm 5.1^{\mathrm{d}}$ & $91.65 \pm 0.82^{\mathrm{b}}$ & $132.00 \pm 5.00^{\mathrm{b}}$ & $40.35 \pm 4.18^{\mathrm{b}}$ & $136.5 \pm 9.00^{c}$ & $0.54 \pm 0.01^{\mathrm{a}}$ & $329.3 \pm 7.3^{\mathrm{a}}$ \\
\hline
\end{tabular}

Values are means \pm standard deviation $(n=3)$.

Values in each column with different small superscript letters are significantly different $(P \leq 0.05)$.

4.84-, 3.45-, and 2.50-fold higher than noted for control cakes $(P<0.05)$. Our results are in agreement with Carlsen et al. [39] where clove and allspice were described as spices with the highest antioxidant potential. The AC provided by photochemiluminescence method (PCL) and measured against $\mathrm{O}_{2}{ }^{-\bullet}$ radicals showed the highest value for cakes enhanced with cloves, followed by enrichment with spice mix, allspice and cinnamon, nutmeg, and finally vanilla. These findings are in accordance with results of Przygodzka et al. [17] who classified cloves, cinnamon, and allspice as group of high antioxidant capacity, nutmeg as middle one, and vanilla as low one. The AC values provided by DPPH test formed the following order: cloves $>$ mix $>$ vanilla $\approx$ cinnamon $>$ allspice $\approx$ nutmeg. These AC values were higher than those for wheat-rye ginger cakes [31]. In our study, a weak positive correlation between TPC and AC provided by DPPH test $(r=0.69)$, by PCL method $(r=0.44)$, and by ABTS assay $(r=$ $0.44)$ was observed. However, higher positive correlations were observed between rutin content and DPPH $(r=$ $0.84)$, PCL $(r=0.98)$, and ABTS $(r=0.69)$. In this study it was confirmed that spices application in rye-buckwheat cakes recipe offered final product with beneficially increased antioxidant capacity as well as phenolic and rutin contents. The slight differences in spices classifications using DPPH, ABTS, and PCL method were observed; however high Pearson correlation coefficients in relation to DPPH versus ABTS $(r=0.94)$, DPPH versus PCL $(r=0.89)$, and ABTS versus PCL $(r=0.90)$ confirmed their convergence.

In recent years, numerous articles published describe an increase of antioxidant activity in cereal-based foods due to the formation of Maillard reaction products (MRPs). It is well known that thermal processing of food often results in loss of nutritional values due to the MR development [40]. It can be expected that enrichment of bakery goods such as cakes with selected spices may inhibit formation of MRPs thus offering a good nutritional value of bakery goods. For this reason, the available lysine content and formation of early, advanced, and final MRPs in rye-buckwheat cakes was further addressed in this study.

3.4. Available Lysine Determination. The results for available lysine content in rye-buckwheat cakes enhanced with selected spices are shown in Table 4.
Available lysine value of $0.52 \mathrm{mg} / \mathrm{g}$ DM was found in control rye-buckwheat cakes. This finding confirmed that common buckwheat flour is a rich source of protein with high nutritional value, especially essential lysine being a limited amino acid in cereals [41]. In this study, a protective effect on lysine blockage was found in rye-buckwheat cakes enhanced with selected spices. The statistically significantly 2 and 3 -fold higher available lysine content was noted in cakes enhanced with allspice, cloves, vanilla, cinnamon, spice mix, and finally nutmeg as compared to rye-buckwheat cakes without spices $(P<0.05)$. It can be concluded that the addition of spices positively influenced the baking process and increased the nutritional value of the final product. The observation of protective effect on lysine blockage in cakes was confirmed by a weak positive correlation between available lysine contents and TPC and rutin contents $(r=0.37$ and $r=0.42$, resp.), as well as AC values provided by ABTS $(r=0.63)$ and DPPH $(r=0.54)$ assays.

3.5. Maillard Reaction Products Evaluation. Early, advanced and final Maillard reaction products contents in rye-buckwheat cakes enriched with spices are shown in Table 4 .

Furosine is considered to be a good marker of early stage of the MR [4]. In our study formation of furosine was confirmed for all types of cakes and inhibition effect of polyphenols on furosine formation was noted in ryebuckwheat cakes enriched with all types of spices. The content of furosine noted in this study was slightly higher than that reported for breakfast cereals [42]; however furosine concentration is in the range for casual prepared food reported by Delgado-Andrade et al. [40]. Significantly decrease of furosine formation (5.6 times lower) was noted in rye-buckwheat cakes with spice mix. Beneficial effect of cloves, allspice, and vanilla application was also observed. It can be resumed that the inhibition effect of polyphenols on furosine formation was found in rye-buckwheat cakes enriched with all types of spices. The high negative correlation between furosine and rutin and TPC contents $(r=-0.91$ and $r=-0.51)$ and furosine versus AC measured by DPPH, PCL, and ABTS $(r=-0.94, r=-0.91, r=-0.99)$ was observed, indicating the link between furosine formation and phenolics content in rye-buckwheat cakes enhanced with spices. It should be also pointed out that furosine data negatively correlated with 
available lysine content $(r=-0.66)$. This relationship is relevant since furosine is a product of the reaction between reactive $\varepsilon$-amino group of lysine and reducing sugars [43].

In this study, the total fluorescence of intermediary compounds (FIC) formed at the advanced MR stage was determined; however a special focus was put on measurement of free and linked-to-protein fluorescent compounds (Table 4). The total and free FIC found in all cakes were within the range of 91.9-146.6 and 73.0-106.9 FI/mg sample DM, respectively, whereas linked-to-protein fluorescent compounds ranged from 18.9 to $47.2 \mathrm{FI} / \mathrm{mg}$ sample DM. Application of spices in rye-buckwheat cake formula decreased free FIC values as compared to control cakes. The significant reduction of free FIC was achieved after addition of cloves, allspice, and cinnamon and then equally spice mix and nutmeg addition. The reduction of free FIC by 31,23 , and $22 \%$ was noted after rye-buckwheat cake enrichment with cloves, allspice, and cinnamon, respectively. The application of spices also reduced the total fluorescence of intermediary compounds (FIC), especially after application of cloves (37\%), vanilla (23\%), and cinnamon (20\%).

The positive effect of phenolics on MRPs formation was noted and confirmed by high negative correlation between rutin content and the total and free FIC values $(r=-0.85$ and $r=-0.72$, resp.). This finding confirmed the positive effect of spices addition on decreasing pool of total free FIC in ryebuckwheat cakes.

To describe the nutritional loss protein damage after baking process FAST index was examined. The calculation of the index was based on the linked-to-protein FIC and the results are presented in Table 4 [34]. The FAST index values for rye-buckwheat cakes enhanced with spices ranged from 68.5 to $154.8 \%$ and were lower as compared to control cake (271.8\%). The use of spice mix, nutmeg, and cloves decrease in rye-buckwheat cakes resulted in reduction of FAST index from 46 up to $50 \%$. The correlation between FAST and furosine was highly positive (0.87); on the other hand negative correlation between FAST index and available lysine content $(r=-0.86)$ was observed. It can be suggested that lysine is limiting factor for fluorescence-chromophores formation and early MR products promote FIC formation.

Different chemical reactions result in many browning products; among others the so-called melanoidins were determined and presented in Table 4 . As it can be observed, brown high molecular polymers of MRPs were formed in control cake without spices and experimental rye-buckwheat cakes with spices addition. After application of spice mix, cloves, cinnamon, and allspice in the recipe significant increase $(P<$ 0.05 ) by $54 \%, 51 \%, 46$, and $31 \%$ in browning was noted, respectively. The values of browning were twice higher than those found in ginger cakes formulated from wheat and rye flours in accordance with Zieliński et al. [44]. Melanoidin formation, expressed in this study as arbitrary absorbance units, was positively correlated with antioxidant capacity measured by DPPH assay $(r=0.71)$, ABTS test $(r=0.54)$, and PCL $(r=$ $0.54)$ and with TPC and rutin contents in the cakes $(r=0.86$ and $r=0.51$ ) as it was previously described by Brudzynski and Miotto [45]. Therefore, it may suggest that antioxidant properties of melanoidin additionally contribute to antioxidant overall. Moreover, a positive correlation between browning and furosine $(r=0.66)$ was observed. In contrast, a correlation between furosine and FAST index was negative $(r=$ -0.68 ). Our findings are in agreement with Pedreschi et al. [46], who also observed strong relationship between acrylamide and brown pigments formation. However, browning and lysine were negatively correlated $(r=-0.61)$. The obtained correlations may suggest that lysine is main precursor of brown pigments formation in rye-buckwheat cakes in established baking conditions. These observations are compatible with postulations made by Hofmann [47] that high molecular weight melanoidins are formed from chromophoric group of low molecular weight melanoidins and amino acids chain of lysine. Moreover this structure is known as pronyl-L-lysine and might contribute to dark colour of product.

3.6. Acrylamide Level. The high interests of undesirable MR product, acrylamide, were detected in buckwheat products with spices. According to results collected in Table 4, the acrylamide was formed in control cake and rye-buckwheat cakes with spices within the range $220.8-329.3 \mu \mathrm{g} / \mathrm{kg} \mathrm{dm}$. Its formation in rye-buckwheat cakes was almost in the same range as the level noted in rye-buckwheat ginger cakes with light buckwheat flour used in formula [10]. According to obtained results, allspice, vanilla, and cloves addition were the most efficient in acrylamide mitigation strategy (8-11\% of acrylamide reduction) which was noted in relation to the control cake without spices. Our studies proved that allspice, vanilla, and cloves application reduced significantly acrylamide content $(P<0.05)$. The good correlation coefficient was calculated between TPC and ACR $(r=0.66)$ and antioxidant activity measured by ABTS method versus ACR $(r=0.62)$. For rutin no correlation was found between ACR formation and rutin content in rye-buckwheat cakes enhanced with spices. In general, our study weakly confirmed the positive impact of phenolics on acrylamide reduction [12]. Moreover, in cakes with spice mix, nutmeg, and cinnamon, the effect of acrylamide promotion was noted [48]. The increase of acrylamide in some samples can be due to theory that polyphenols with carbonyl groups react with asparagine and formed acrylamide [49] and following Cheng et al. [11], it can be concluded that only moderate amount of antioxidants application can reduce acrylamide.

\section{Conclusions}

Rutin, bioactive compound characteristic for buckwheat, increased after cloves, allspice, and spice mix addition, and cakes with cloves and allspice showed the highest level of available lysine. The highest TPC values were obtained for cakes with spice mix, cloves, and cinnamon. According to ABTS and PCL methods, cloves and spice mix had significantly highest antioxidant capacity. Furosine content was decreased after application of cloves, allspice, spice mix, and vanilla to cake formula. Total and free fluorescent intermediatory compounds (FIC) values decreased in samples with cloves, allspice, and cinnamon. The FAST index decreased in all types of cakes fortified with spices, especially after cloves, 
allspice, and spice mix addition. Cloves, allspice, and vanilla added to cake formula were the most efficient in acrylamide mitigation strategy as $8-11 \%$ of acrylamide reduction was noted. The high values of browning index were obtained in cakes with cloves, cinnamon, and spice mix.

According to obtained results, it can be suggested that cloves, allspice, and spice mix should be used for production of safety and good quality cakes. Our results could be utilised in the development of a new, health-beneficial, functional cakes with enhanced antioxidant activity.

\section{Disclosure}

The paper is a part of the Ph.D. thesis of Małgorzata Przygodzka.

\section{Conflict of Interests}

The authors declare that there is no conflict of interests regarding the publication of this paper.

\section{Acknowledgment}

This research was supported by Grant no. 2012/07/N/NZ9/ 02250 from National Science Centre.

\section{References}

[1] D. S. Mottram, "The Maillard reaction: source of flavor in thermally processed foods," in Flavour and Frangrances, R. G. Berg, Ed., pp. 269-283, Springer, Berlin, Germany, 2007.

[2] D. H. M. Bastos and A. Gugliucci, "Contemporary and controversial aspects of the Maillard reaction products," Current Opinion in Food Science, vol. 1, pp. 13-20, 2015.

[3] D. Virág, A. Kiss, P. Forgó, C. Csutorás, and S. Molnár, "Study on Maillard-reaction driven transformations and increase of antioxidant activity in lysine fortified biscuits," Microchemical Journal, vol. 107, pp. 172-177, 2013.

[4] V. Gökmen, A. Serpen, Ö. Ç. Açar, and F. J. Morales, "Significance of furosine as heat-induced marker in cookies," Journal of Cereal Science, vol. 48, no. 3, pp. 843-847, 2008.

[5] V. Giannetti, M. B. Mariani, P. Mannino, and E. Testani, "Furosine and flavour compounds in durum wheat pasta produced under different manufacturing conditions: multivariate chemometric characterization," LWT_Food Science and Technology, vol. 56, no. 1, pp. 15-20, 2014.

[6] D. R. Lineback, J. R. Coughlin, and R. H. Stadler, "Acrylamide in foods: a review of the science and future considerations," Annual Review of Food Science and Technology, vol. 3, no. 1, pp. 15-35, 2012.

[7] C. Delgado-Andrade, I. Seiquer, M. P. Navarro, and F. J. Morales, "Maillard reaction indicators in diets usually consumed by adolescent population," Molecular Nutrition and Food Research, vol. 51, no. 3, pp. 341-351, 2007.

[8] A. Liogier de Sereys, S. Muller, S. D. Desic et al., "Potential of the FAST index to characterize infant formula quality," in Handbook of Dietary and Nutritional Aspects of Bottle Feeding, V. R. Preedy, R. R. Watson, and S. Zibadi, Eds., vol. 8 of Human Health Handbooks, pp. 457-475, Wageningen Academic Publishers, 2014.
[9] E. Langner and W. Rzeski, "Biological properties of melanoidins: a review," International Journal of Food Properties, vol. 17, no. 2, pp. 344-353, 2014.

[10] L. Marková, Z. Ciesarová, K. Kukurová et al., "Influence of various spices on acrylamide content in buckwheat ginger cakes," Chemical Papers, vol. 66, no. 10, pp. 949-954, 2012.

[11] J. Cheng, X. Chen, S. Zhao, and Y. Zhang, "Antioxidant-capacity-based models for the prediction of acrylamide reduction by flavonoids," Food Chemistry, vol. 168, pp. 90-99, 2015.

[12] R. A. Oral, M. Dogan, and K. Sarioglu, "Effects of certain polyphenols and extracts on furans and acrylamide formation in model system, and total furans during storage," Food Chemistry, vol. 142, pp. 423-429, 2014.

[13] D. Dziki, R. Różyło, U. Gawlik-Dziki, and M. Świeca, “Current trends in the enhancement of antioxidant activity of wheat bread by the addition of plant materials rich in phenolic compounds," Trends in Food Science \& Technology, vol. 40, no. 1, pp. 48-61, 2014.

[14] A. Wojdyło, J. Oszmiański, and R. Czemerys, "Antioxidant activity and phenolic compounds in 32 selected herbs," Food Chemistry, vol. 105, no. 3, pp. 940-949, 2007.

[15] I. Hinneburg, H. J. Damien Dorman, and R. Hiltunen, "Antioxidant activities of extracts from selected culinary herbs and spices," Food Chemistry, vol. 97, no. 1, pp. 122-129, 2006.

[16] D. J. Charles, "Natural antioxidants," in Antioxidant Properties of Spices, Herbs and Other Sources, pp. 39-64, Springer, New York, NY, USA, 2013.

[17] M. Przygodzka, D. Zielińska, Z. Ciesarová, K. Kukurová, and H. Zieliński, "Comparison of methods for evaluation of the antioxidant capacity and phenolic compounds in common spices," LWT-Food Science and Technology, vol. 58, no. 2, pp. 321-326, 2014.

[18] M. H. Carlsen, R. Blomhoff, and L. F. Andersen, "Intakes of culinary herbs and spices from a food frequency questionnaire evaluated against 28-days estimated records," Nutrition Journal, vol. 10, article 50, 2011.

[19] C. M. Kaefer and J. A. Milner, "The role of herbs and spices in cancer prevention," The Journal of Nutritional Biochemistry, vol. 19, no. 6, pp. 347-361, 2008.

[20] R. Cazzola and B. Cestaro, "Antioxidant spices and herbs used in diabetes," in Diabetes: Oxidative Stress and Dietary Antioxidants, V. Preedy, Ed., chapter 9, pp. 89-97, Academic Press, London, UK, 2014.

[21] M. E. Embuscado, "Herbs and spices as antioxidants for food preservation," in Handbook of Antioxidants for Food Preservation, F. Shahidi, Ed., Woodhead Publishing Series in Food Science, Technology and Nutrition, pp. 251-283, Springer, Berlin, Germany, 2015.

[22] V. V. Illupapalayam, S. C. Smith, and S. Gamlath, "Consumer acceptability and antioxidant potential of probiotic-yogurt with spices," LWT-Food Science and Technology, vol. 55, no. 1, pp. 255-262, 2014.

[23] A. Wójtowicz, A. Kolasa, and L. Mościcki, "Influence of buckwheat addition on physical properties, texture and sensory characteristics of extruded corn snacks," Polish Journal of Food and Nutrition Sciences, vol. 63, no. 4, pp. 239-244, 2013.

[24] B. Krkošková and Z. Mrázová, "Prophylactic components of buckwheat," Food Research International, vol. 38, no. 5, pp. 561568, 2005.

[25] I. Sedej, M. Sakač, A. Mandić et al., "Quality assessment of gluten-free crackers based on buckwheat flour," LWT-Food Science and Technology, vol. 44, no. 3, pp. 694-699, 2011. 
[26] J. Chlopicka, P. Pasko, S. Gorinstein, A. Jedryas, and P. Zagrodzki, "Total phenolic and total flavonoid content, antioxidant activity and sensory evaluation of pseudocereal breads," LWT_Food Science and Technology, vol. 46, no. 2, pp. 548-555, 2012.

[27] M. Wronkowska, A. Troszyńska, M. Soral-Śmietana, and A. Wołejszo, "Effects of buckwheat flour (Fagopyrum esculentum Moench) on the quality of gluten-free bread," Polish Journal of Food and Nutrition Sciences, vol. 58, no. 2, pp. 211-216, 2008.

[28] B. Filipčev, O. Šimurina, M. Sakač et al., "Feasibility of use of buckwheat flour as an ingredient in ginger nut biscuit formulation," Food Chemistry, vol. 125, no. 1, pp. 164-170, 2011.

[29] ISO, "Sensory analysis-methodology—general guidance for establishing a sensory profile," ISO/DIS 13299, International Organization for Standardization, Geneva, Switzerland, 1998.

[30] H. Stone, R. N. Bleibaum, and H. A. Thomas, Eds., Sensory Evaluation Practices, Academic Press, New York, NY, USA, 4th edition, 2012.

[31] H. Zieliński, M. D. del Castillo, M. Przygodzka, Z. Ciesarova, K. Kukurova, and D. Zielińska, "Changes in chemical composition and antioxidative properties of rye ginger cakes during their shelf-life," Food Chemistry, vol. 135, no. 4, pp. 2965-2973, 2012.

[32] D. Zielińska, D. Szawara-Nowak, and H. Zieliński, "Determination of the antioxidant activity of rutin and its contribution to the antioxidant capacity of diversifed buckwheat origin material by updated analytical strategies," Polish Journal of Food and Nutrition Sciences, vol. 60, no. 4, pp. 315-321, 2010.

[33] A. Michalska, M. Amigo-Benavent, H. Zielinski, and M. D. del Castillo, "Effect of bread making on formation of Maillard reaction products contributing to the overall antioxidant activity of rye bread," Journal of Cereal Science, vol. 48, no. 1, pp. 123-132, 2008.

[34] C. Delgado-Andrade, J. A. Rufián-Henares, and F. J. Morales, "Study on fluorescence of Maillard reaction compounds in breakfast cereals," Molecular Nutrition and Food Research, vol. 50, no. 9, pp. 799-804, 2006.

[35] D. Janeš, D. Kantar, S. Kreft, and H. Prosen, "Identification of buckwheat (Fagopyrum esculentum Moench) aroma compounds with GC-MS," Food Chemistry, vol. 112, no. 1, pp. 120124, 2009.

[36] M. A. J. S. van Boekel, "Formation of flavour compounds in the Maillard reaction," Biotechnology Advances, vol. 24, no. 2, pp. 230-233, 2006.

[37] I. Kreft, N. Fabjan, and K. Yasumoto, "Rutin content in buckwheat (Fagopyrum esculentum Moench) food materials and products," Food Chemistry, vol. 98, no. 3, pp. 508-512, 2006.

[38] E. Sofic, A. Copra-Janicijevic, M. Salihovic, I. Tahirovic, and G. Kroyer, "Screening of medicinal plant extracts for quercetin3rutinoside (rutin) in Bosnia and Herzegovina," Medicinal Plants, vol. 2, no. 2, pp. 97-102, 2010.

[39] M. H. Carlsen, B. L. Halvorsen, K. Holte et al., "The total antioxidant content of more than 3100 foods, beverages, spices, herbs and supplements used worldwide," Nutrition Journal, vol. 9, no. 1, article 3, 2010.

[40] C. Delgado-Andrade, I. Seiquer, A. Haro, R. Castellano, and M. P. Navarro, "Development of the Maillard reaction in foods cooked by different techniques. Intake of Maillard-derived compounds," Food Chemistry, vol. 122, no. 1, pp. 145-153, 2010.

[41] E. Arendt and E. Zannini, "Buckwheat," in Cereal Grains for the Food an Beverage Industries, pp. 369-408, Woodhead Publishing, London, UK, 2013.
[42] J. A. Rufián-Henares, C. Delgado-Andrade, and F. J. Morales, "Analysis of heat-damage indices in breakfast cereals: influence of composition," Journal of Cereal Science, vol. 43, no. 1, pp. 6369, 2006.

[43] J. A. Rufián-Henares, B. García-Villanova, and E. GuerraHernández, "Furosine content, loss of o-phthaldiadehyde reactivity, fluorescence and colour in stored enteral formulas," International Journal of Dairy Technology, vol. 55, no. 3, pp. 121126, 2002.

[44] H. Zieliński, M. Amigo-Benavent, M. D. del Castillo, A. Horszwald, and D. Zielińska, "Formulation and baking process affect Maillard reaction development and antioxidant capacity of ginger cakes," Journal of Food and Nutrition Research, vol. 49, no. 3, pp. 140-148, 2010.

[45] K. Brudzynski and D. Miotto, "Honey melanoidins: analysis of the compositions of the high molecular weight melanoidins exhibiting radical-scavenging activity," Food Chemistry, vol. 127, no. 3, pp. 1023-1030, 2011.

[46] F. Pedreschi, P. Moyano, K. Kaack, and K. Granby, "Color changes and acrylamide formation in fried potato slices," Food Research International, vol. 38, no. 1, pp. 1-9, 2005.

[47] T. Hofmann, "Studies on melanoidin-type colorants generated from the Maillard reaction of protein-bound lysine and furan-2-carboxaldehyde-chemical characterisation of a red coloured domaine," Zeitschrift für Lebensmitteluntersuchung und-Forschung A, vol. 206, no. 4, pp. 251-258, 1998.

[48] C. Jin, X. Wu, and Y. Zhang, "Relationship between antioxidants and acrylamide formation: a review," Food Research International, vol. 51, no. 2, pp. 611-620, 2013.

[49] A. Hamzalığlu, B. A. Mogol, R. B. Lumaga, V. Fogliano, and V. Gökmen, "Role of curcumin in the conversion of asparagine into acrylamide during heating," Amino Acids, vol. 44, no. 6, pp. 1419-1426, 2013. 

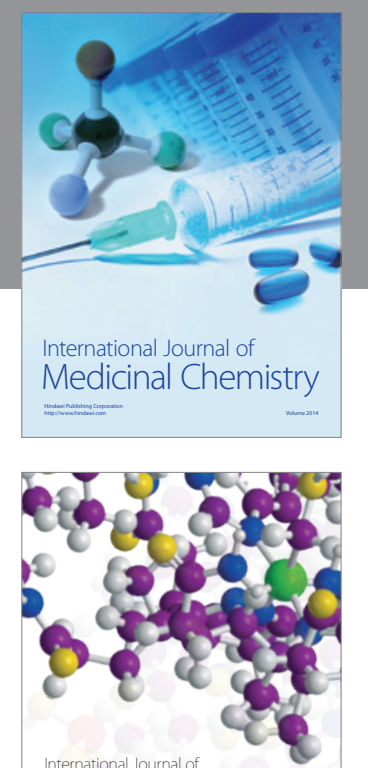

\section{Carbohydrate} Chemistry

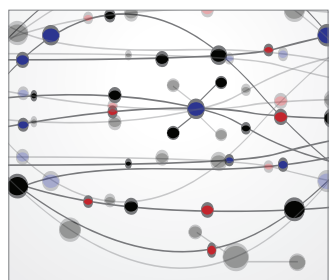

The Scientific World Journal
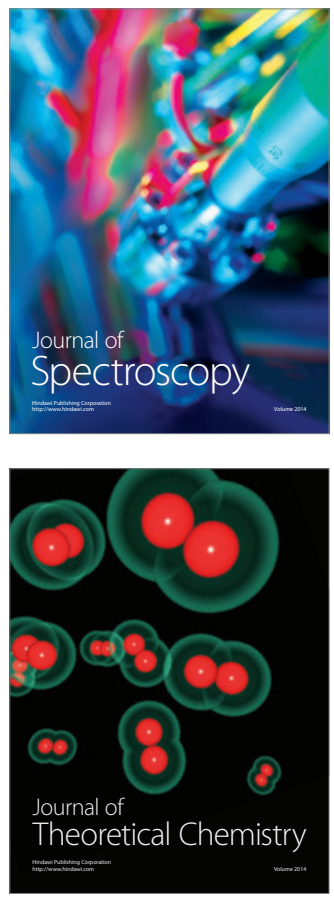
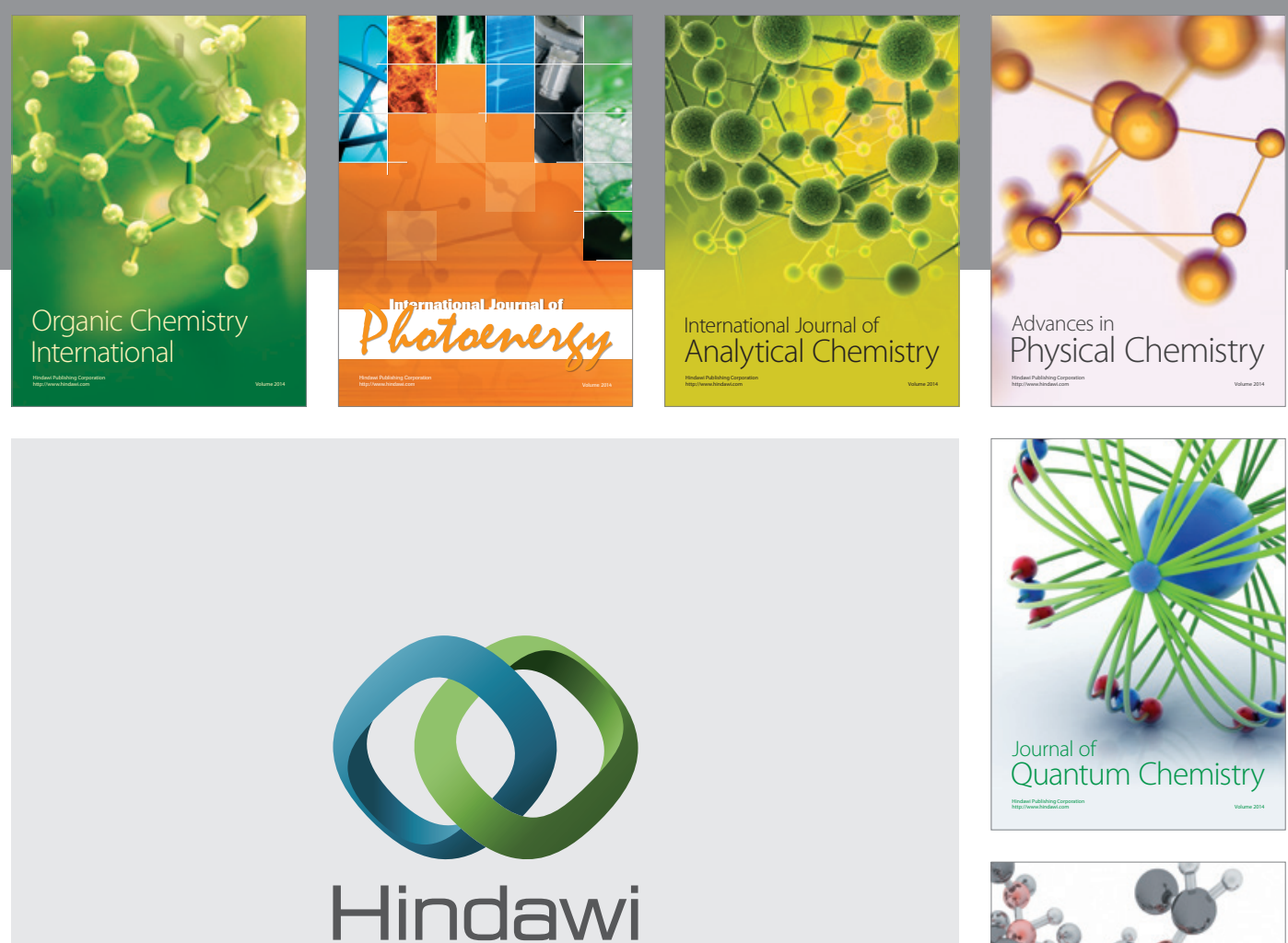

Submit your manuscripts at

http://www.hindawi.com

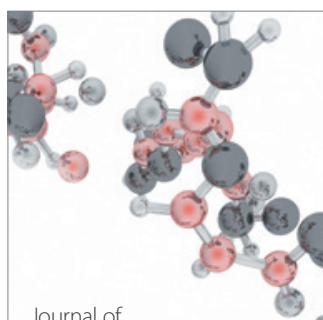

Analytical Methods

in Chemistry

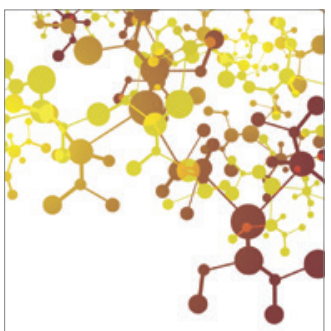

Journal of

Applied Chemistry

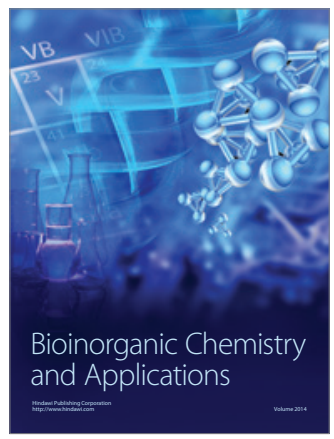

Inorganic Chemistry
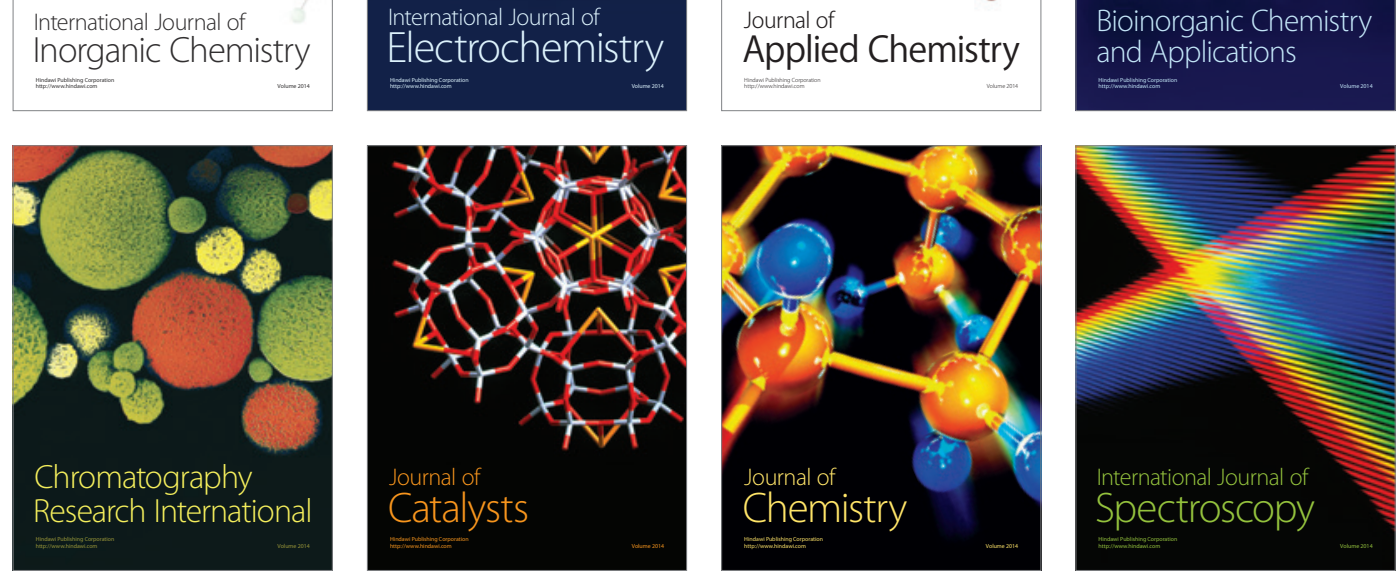